\title{
An Empirical Analysis on the Stable Return of Resident Funds
}

\author{
Jinling He${ }^{1}$, Zixiang Xia', Jingcheng $\mathrm{He}^{2}$, Xin Gao ${ }^{*}$ \\ ${ }^{1}$ School of science, Yunnan Agricultural University, Kunming 650201, Yunnan Province, China \\ 2The First Company of China Eighth Engineering Bureau Led, Jinan 250101, Shandong Province, China \\ *Corresponding author: Xin Gao, amonggx@sina.com
}

\begin{abstract}
This paper mainly studies how investors invest in funds to obtain high returns while avoiding risks. Firstly, from the perspective of portfolio investment, this paper introduces the traditional Markowitz mean-variance model and capital asset pricing model (CAPM), then selects four funds from different industries by MATLAB program in Sina Finance and Economics Network for application analysis from which the optimal portfolio point can be obtained under the combination of efficient frontier and capital allocation line. Subsequently, by analyzing the returns of long-term holdings and short-term operations of Noan Growth Hybrid Fund, it is confirmed that long-term holding funds can better cope with the changing market so as to obtain more stable returns. Finally, this paper discusses the dynamic adjustments of asset portfolio. Resident investors are supposed to take into account the market situation and the changes of the fund itself to adjust the holding fund portfolio. Based on the research in this paper, resident investors ought to combine investment funds to diversify risk allocation and make long-term holding plans according to their risk tolerance. At the same time, they should also make appropriate dynamic adjustments when the external environment changes to ensure long-term benefits.
\end{abstract}

Keywords: Portfolio investment; Mean-variance model; Long-term investment; CAPM; Dynamic adjustment

Publication date: August 2021; Online publication: August 30, 2021

\section{Introduction}

With the continuous development of China's economy, the income levels of residents along with consumer expenditure have increased significantly, which result in resident investors seeking more moderate financial investment products. In the context of the increasingly perfect capital market operation mechanism and system, residents' asset allocation has also undergone tremendous adjustments. Compared with high-risk stocks, high-threshold growth enterprises market (GEM), science and technology board, and Hong Kong stock market, funds with advantages of collective investment and risk diversification have become the preferred investment for residents. People entrust their funds to special fund managers to carry out investment management. Fund managers pool funds from many investors and invest these funds according to their professional abilities to achieve the purpose of reducing investment costs and dispersing risks. This paper studies how residents should invest funds to obtain stable returns from portfolio management and fund holding.

\section{Portfolio management}

\subsection{Related theory}

A portfolio is a collection of stocks, bonds, and financial derivatives held by investors or financial institutions with the aim of diversifying risks; namely, "don't put all your eggs in one basket." Based on 
the core idea of a portfolio, Harry Markowitz ${ }^{[1]}$ first proposed the mean-variance model (MVO), which marked the beginning of the modern portfolio theory (MPT). On the theoretical basis of the investment portfolio constructed by the mean-variance analysis framework of Markowitz for security return and risk, Sharpe ${ }^{[2]}$, Lintner ${ }^{[3]}$, and Mossin ${ }^{[4]}$ established a single-period capital asset pricing model (CAPM) that determines the relationship between the expected return for assets and the systematic risk so that the connection between the expected profit and the risk that investors face can be explained by the capital market curve and the security market curve, which in turn provide investors with a theoretical guidance for combination investment.

\subsection{Markowitz mean-variance model}

The mean-variance model ${ }^{[5]}$ was first put forward by Markowitz in 1952, which uses mean and variance to represent the return and risk of assets, respectively, and translates asset allocation problem into a quadratic programming problem with linear constraints. The famous Markowitz portfolio model is established by seeking portfolios with minimum risk or with maximum return under given risk in which the set of portfolios satisfying the above two conditions is called an efficient set or efficient frontier ${ }^{[6]}$. Assuming that investors invest in two kinds of securities $-\mathrm{i}$ and $\mathrm{j}, \mathrm{x}_{\mathrm{i}}$ means the proportion of funds invested in security $\mathrm{i}, \sigma_{i}$ means the risk of security $\mathrm{i}$, and the total proportion of all investments, $\sum \mathrm{i} \leq 1$, does not exceed the budget. The expected return $r_{i}$ of security $i$ is $E\left(r_{i}\right)$, and the covariance of return of the two securities is $\operatorname{cov}\left(\mathrm{r}_{\mathrm{i}}, \mathrm{r}_{\mathrm{j}}\right)$, which is used to measure the correlation between the yield rate of the two assets. The expected return of the portfolio is $\sum_{\mathrm{x}_{\mathrm{i}}} \mathrm{E}\left(\mathrm{r}_{\mathrm{i}}\right)$, which is expected to be $\mu$. The proportion of the investment in securities $i$ and $j$ is adjusted to minimize the risk of the portfolio. The mathematical model is as follows:

$$
\begin{gathered}
\min \sigma^{2}=\operatorname{var}\left(\sum_{i} x_{i} r_{i}\right)=\sum_{i j} x_{i} x_{j} \operatorname{cov}\left(r_{i}, r_{j}\right)=x_{i}^{2} \sigma_{i}^{2}+x_{j}^{2} \sigma_{j}^{2}+2 x_{i} x_{j} \operatorname{cov}\left(r_{i}, r_{j}\right) \\
\text { s.t } \sum_{i} x_{i} E\left(r_{i}\right) \geq \mu \\
\sum_{i} x_{i} \leq 1
\end{gathered}
$$

The risk of portfolio mainly depends on the investment proportion of each asset and the correlation coefficient between different securities. Therefore, priority should be given to select assets with small variance and low correlation coefficient between the two in building portfolios to reduce the investment risk. In practical application, the sample mean and sample variance of past earnings data are usually used to estimate the future earnings and risks ${ }^{[7]}$.

Taking risk as the abscissa and return as the ordinate, it can be seen from equation (1) that return is a monotonically increasing function of risk, and when the correlation between the two assets in the portfolio reduces, the risk to obtain the same return is smaller. Therefore, return is a monotonically increasing convex function of risk, from which the minimum-variance frontier of the portfolio can be obtained. Generally, a portfolio with the least risk among all possible portfolios is usually called a global minimum variance portfolio (GMVP). Since investors are rational, under the same risk, they will choose a higher return; that is, the curve that tilts above the GMVP point to the upper right is the optimal choice for investors, which is called the efficient frontier of portfolios and this reflects the basic principle of "high return and high risk" in investment as shown in Figure $1^{[8]}$. 


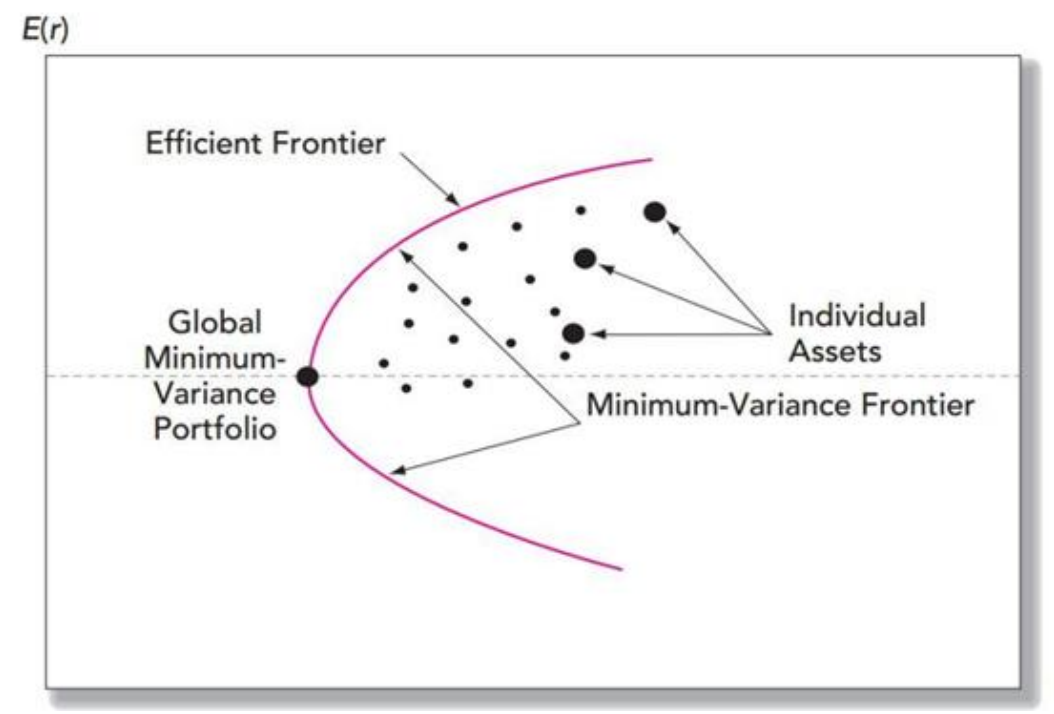

Figure 1. Minimum-variance frontier

\subsection{Asset pricing model}

On the basis of Markowitz efficient frontier, William Sharp introduces risk-free assets where he combines risk-free assets with risky portfolios on the efficient boundary. The feasible set of risk and return formed by the new portfolio is called capital allocation line (CAL) as shown in Figure $2^{[8]}$. Based on the above risky assets, $i$ and $j$, supposing that $p$ is the portfolio formed by the risky assets on the efficient frontier, the investment weight and risk of portfolio $\mathrm{p}$ are $\mathrm{w}_{1}$ and $\delta_{\mathrm{p}}$, respectively. The investment weight and risk of risk-free assets are $\mathrm{w}_{2}\left(1-\mathrm{w}_{1}\right)$ and $\delta_{\mathrm{f}}=0$, respectively. $\mathrm{R}_{\mathrm{P}}$ and $\delta_{\mathrm{P}}$ are the expected return and risk of the new portfolio formed by $\mathrm{p}$ and risk-free assets. Then, the following equation is established:

$$
\begin{gathered}
R_{P}=\left(1-w_{1}\right) R_{f}+w_{1} R_{p} \\
\sigma_{P}=\sqrt{w_{1}{ }^{2} \delta_{p}{ }^{2}}
\end{gathered}
$$

Simplified as:

$$
R_{P}=R_{f}+\left(R_{p}-R_{f}\right) \frac{\delta_{P}}{\delta_{p}}
$$

Equation (6) shows that $\mathrm{R}_{\mathrm{P}}$ and $\delta_{\mathrm{P}}$ are linear so the capital allocation line formed is a straight line. The longitudinal intercept is the expected return $R_{P}$ of the new portfolio (at point $F$ in Figure 2), and the slope is Sharpe ratio $\frac{\mathrm{R}_{\mathrm{p}}-\mathrm{R}_{\mathrm{f}}}{\delta_{p}}$, namely the unit risk compensation. When the slope is the largest, the capital allocation line is tangent to the efficient frontier and the expected return reaches the maximum (at point $\mathrm{P}$ in Figure 2). In the premise of risk-free lending, the point on the line segment of FP extension line is a feasible portfolio, which is better than the part above point $\mathrm{P}$ on the efficient boundary. 


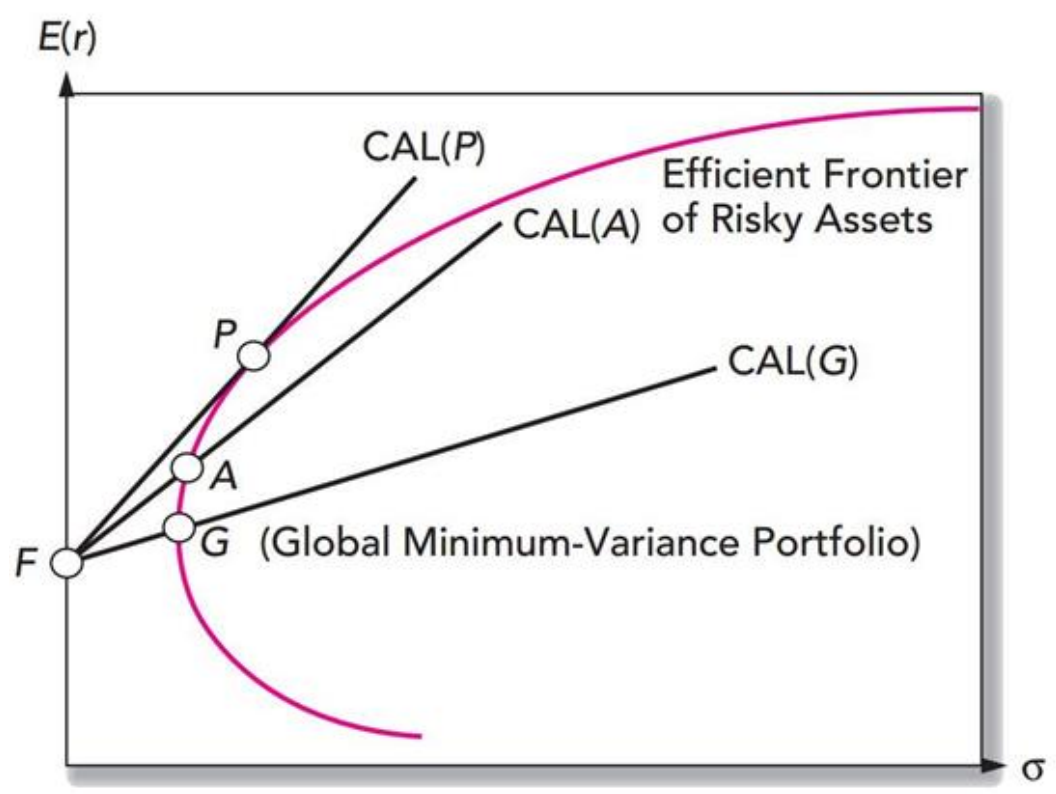

Figure 2. Capital allocation line

\subsection{Empirical analysis}

The portfolio theory can provide theoretical guidance for resident investing funds to achieve the goal of maximizing risk diversification and seeking greater returns. Based on the dual consideration of security and profitability, residents should cooperate with risk-free funds to ensure asset security in portfolio investment while investing in risk funds to obtain benefits. Furthermore, the risk in a poor portfolio of risk funds may be greater so investors should also reasonably distinguish between portfolios to avoid excessive risks.

This paper selects four funds, namely Bank of China New Energy Theme Hybrid Fund (002190), Hua'an Anxin Consumer Hybrid (519002), Changxin Healthcare Hybrid (LOF) (163001), and Noan Growth Hybrid Fund (320007). As they belong to different industries, the correlation between funds is relatively low, which fully meet the characteristics of portfolio dispersion. Firstly, the historical data of the four funds are processed, and the Markowitz minimum variance efficient boundary of the fund portfolio is drawn. Then, the risk-free asset (assuming that its risk-free interest rate is $0 \%$ ) is added to combine it with the portfolio on the efficient boundary to determine the optimal portfolio allocation of the four funds considering the risk-free asset.

The net daily unit values of the four funds from January 1, 2018, to April 1, 2021, are selected as the sample data. The selected data are obtained from Sina Finance and Economics Network through MATLAB. The net daily unit values of the four funds are shown in Figure 3. By processing these data with Excel, the annual rate of return for each fund as well as the mean and variance of the annual rate of return is obtained. 


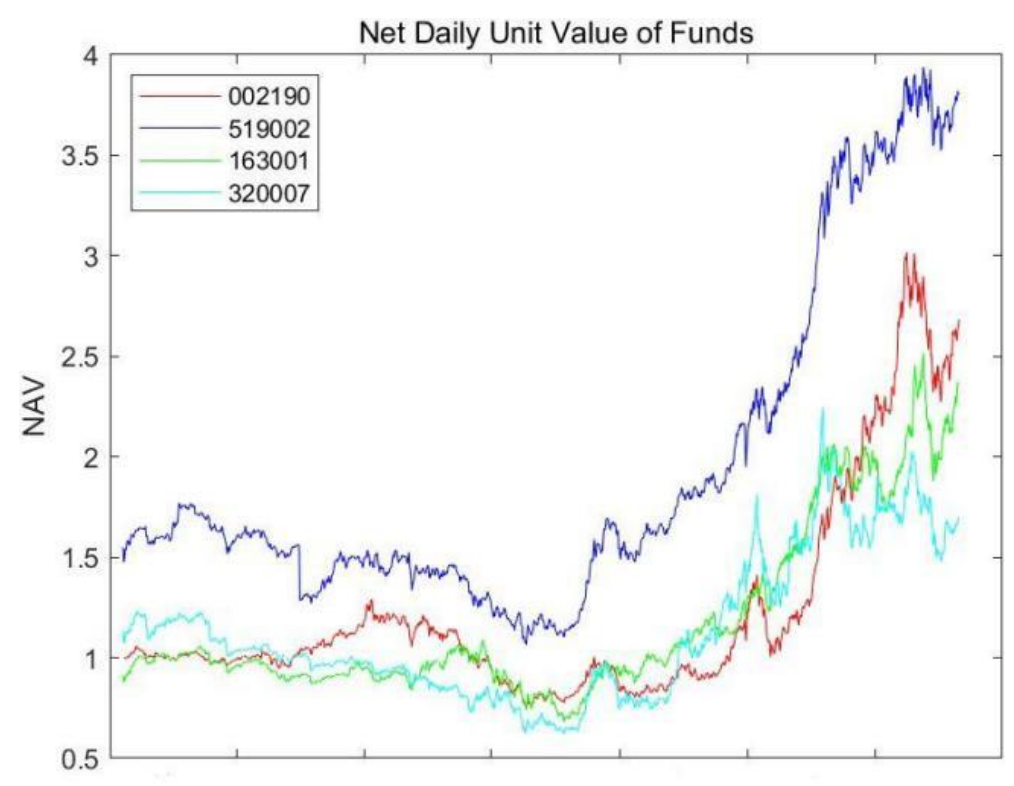

Figure 3. Diurnal chart of net daily unit value of funds

The net daily unit value of each fund is processed. For the yield of single investment, the logarithmic yield sequence can be added, which is convenient for practical operation with high credibility. Assuming that $r_{i t}$ is the yield of fund $i$ during period $t, P_{i t}$ is the net daily unit value of fund $i$ during period $t$, and $P_{i t-1}$ is the net daily unit value of during period $t-1$, where $i=1,2,3,4$, and $t=1,2,3, \ldots, 1197$. The daily rate of return of each fund can be obtained using the formula as follows:

$$
r_{i t}=L N\left(\frac{P_{i t}}{P_{i t-1}}\right)
$$

EXCEL software is used for perspective analysis of the data to calculate the annual return of each fund. The mean, variance, standard deviation, and covariance of the annual return of each fund are obtained as follows as shown in Table 1 and Table 2.

Table 1. Mean, variance, and standard deviation of the annual return of each fund from January 1, 2018, to April 1, 2021

\begin{tabular}{lcccc}
\hline & 002190 & 519002 & 163001 & 320007 \\
\hline Mean & 0.588624358 & 0.393188511 & 0.548008579 & 0.548895628 \\
Variance & 0.378838364 & 0.372854117 & 0.33295126 & 0.310550205 \\
Standard deviation & 0.615498468 & 0.610617816 & 0.577019289 & 0.557270316 \\
\hline
\end{tabular}

Table 2. Covariance matrix of the annual return of each fund from January 1, 2018, to April 1, 2021

\begin{tabular}{ccccc}
\hline & 002190 & 519002 & 163001 & 320007 \\
\hline 002190 & 0.378838364 & 0.341507307 & 0.313885571 & 0.313577145 \\
519002 & 0.341507307 & 0.372854117 & 0.317936582 & 0.31297596 \\
163001 & 0.313885571 & 0.317936582 & 0.33295126 & 0.301660289 \\
320007 & 0.313577145 & 0.31297596 & 0.301660289 & 0.310550205 \\
\hline
\end{tabular}


The investment weight of each fund is calculated respectively when the risk-free interest rate is $1 \%$ and $35 \%$. Assuming that $\mathrm{S}$ as the covariance matrix of fund return, $\mathrm{E}(\mathrm{r})$ is the average annual return, $\mathrm{C}$ is the risk-free interest rate, $x_{i}$ is the investment ratio of each asset, $E\left(r_{x}\right)$ is the expected return of the new portfolio, and $\operatorname{Var}(\mathrm{x})$ is the income variance of the new portfolio. The investment weight of each fund is calculated by the following formulas:

$$
\begin{gathered}
x_{i}=\frac{S^{-1}\{E(r)-C\}}{\sum_{j=1}^{N} z_{i}} \\
z_{i}=S^{-1}\{E(r)-C\} \\
E\left(r_{x}\right)=\sum_{i}^{N} x_{i} E\left(r_{i}\right) \\
\operatorname{Var}(x)=\sum_{i}^{N} x_{i} \sum_{j}^{N} x_{j} \sigma_{i j}
\end{gathered}
$$

Using the formula GMVP $=\frac{\{1, \ldots, 1\} \mathrm{S}^{-1}}{\{1, \ldots, 1\} \mathrm{S}^{-1}\{1, \ldots, 1\}^{-1}}$, the global minimum variance portfolio (GMVP) is obtained. By changing the proportion of the portfolio, the expected return and risk of the portfolio under different proportions of the new portfolio are simulated through the function of the simulation operation table in Excel, and then the efficient boundary of the portfolio; namely, the red curve above the GMVP point is drawn as shown in Figure 4. The risk-free assets with risk-free interest rate of $0 \%$ and the portfolio on the efficient boundary are combined to obtain the capital allocation line of risk-free assets and risk assets as shown as the yellow line in Figure 4. The optimal portfolio is drawn in Excel as following:

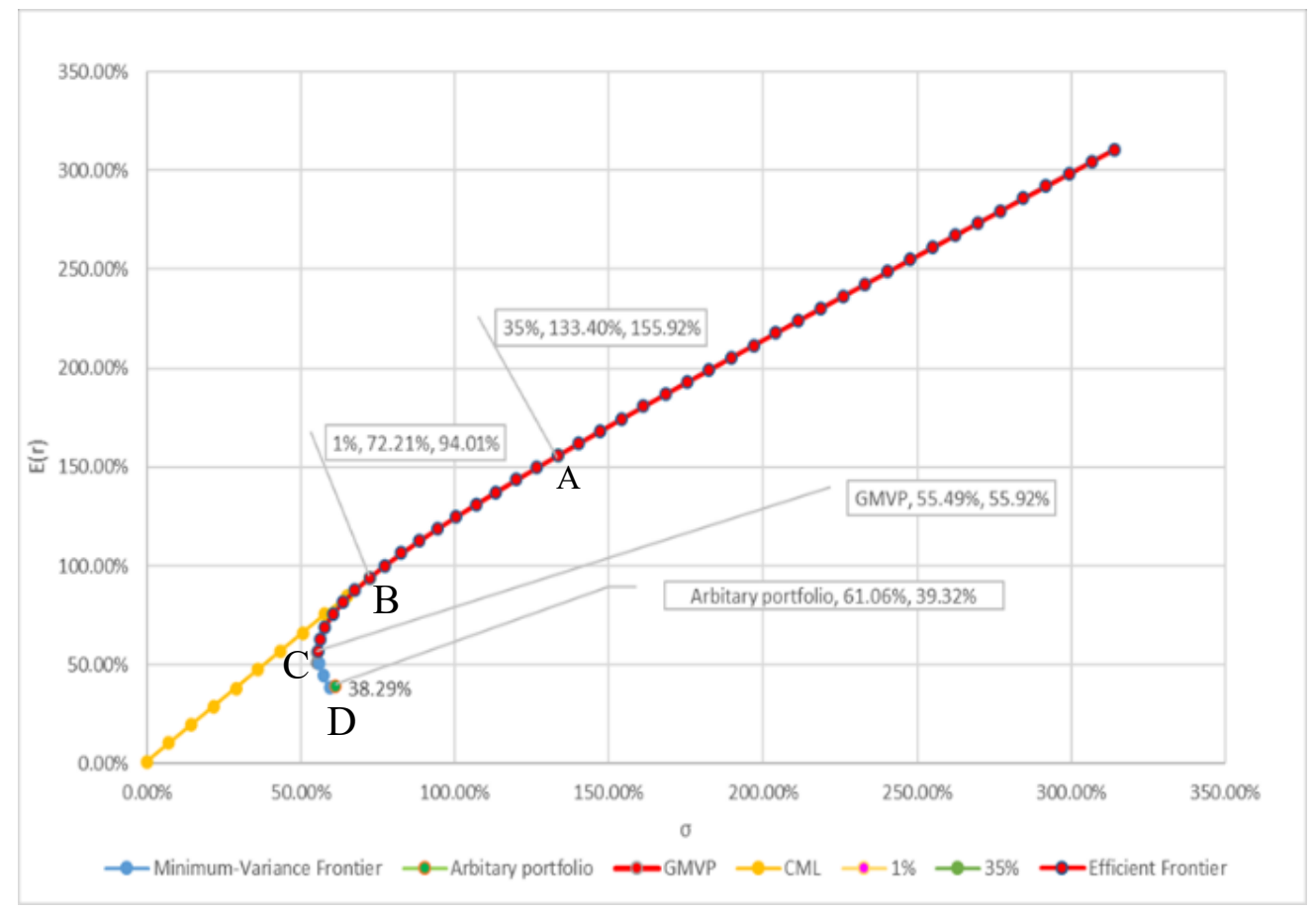

Figure 4. Optimal asset portfolio 
As can be seen from the figure above, the portfolios with the lowest risk of the four funds are on the efficient boundary at risk-free rates of $1 \%$ and $35 \%$ (red curve in Figure 4). When investing in a fund alone, taking Hua' an Anxin Consumer Hybrid as an example, its return on investment is $39.32 \%$ whereas the risk is $61.06 \%$ (point D in Figure 4). This point falls below the GMVP (point C in Figure 4), which is an invalid combination because the portfolio investment on the efficient frontier has higher return and lower risk than the single investment. The calculated portfolio investment is shown in Table 3.

Table 3. Portfolio results

\begin{tabular}{lcccc}
\hline & & Envelope part1 & Envelope part2 & GMVP \\
\hline Risk-free interest rate & $1 \%$ & $1 \%$ & $35 \%$ & - \\
002190 & $0.00 \%$ & $111.70 \%$ & $302.01 \%$ & $-5.40 \%$ \\
519002 & $100.00 \%$ & $-223.15 \%$ & $-572.63 \%$ & $-8.13 \%$ \\
163001 & $0.00 \%$ & $72.24 \%$ & $147.13 \%$ & $26.16 \%$ \\
320007 & $0.00 \%$ & $139.22 \%$ & $223.49 \%$ & $87.37 \%$ \\
Sum of weight & $100.00 \%$ & $100.00 \%$ & $100.00 \%$ & $100.00 \%$ \\
E(r) & $39.32 \%$ & $94.01 \%$ & $155.92 \%$ & $55.92 \%$ \\
Var & $37.29 \%$ & $52.14 \%$ & $177.96 \%$ & $30.79 \%$ \\
Sigma & $61.06 \%$ & $72.21 \%$ & $133.40 \%$ & $55.49 \%$ \\
Sharpe ratio & $56.20 \%$ & $128.81 \%$ & $90.64 \%$ & - \\
\hline
\end{tabular}

The Sharpe ratio of all portfolios is positive. The portfolio on the efficient boundary achieves the minimum investment risk at the same return level and the highest return at the same risk level. Figure 4 shows that when the risk-free interest rate is $1 \%$, the investment ratios of envelope part1 are $111.7 \%$, $223.25 \%, 72.24 \%$, and $139.22 \%$, respectively, indicating that investors are financed in accordance with the risk-free interest rate and are fully invested in the market portfolio; that is, Hua'an Anxin Consumer Hybrid to invest in the other three funds. At this time, equation (10) shows that the expected return of envelope part1 is $\mathrm{E}\left(\mathrm{r}_{\mathrm{x}}\right)=\sum_{\mathrm{i}}^{N} \mathrm{x}_{\mathrm{i}} \mathrm{E}\left(\mathrm{r}_{\mathrm{i}}\right)=94.01 \%$. Although its risk is greater than $61.06 \%$ of the portfolio at point D in Figure 4, its return is much greater than 39.32\% of the portfolio at point D, hence this portfolio is suitable for risk averse investors. The portfolio at GMVP is the global minimum variance portfolio, where the risk is $55.49 \%$ and the return is $55.92 \%$, which is better than the portfolio at point $\mathrm{D}$ and is conducive for risk neutral investors. Based on the above analysis, it can be seen that the portfolio on the efficient boundary is better than the return of a single fund, which reflects the advantages of portfolio investment in dispersing risk and improving return. Moreover, the portfolio on the efficient frontier effectively reflects the basic principle of high return, high risk.

\section{Portfolio holding strategy}

In addition to portfolio investment to avoid risks, investors should master the correct holding strategy. The strategy of buying and holding is simple, and its theoretical basis is time to create value. With the passage of time, the intrinsic value of outstanding listed companies improves, and the net value of funds can be continuously innovated. Therefore, investors should adhere to long-term holding. Besides, buying and holding does not mean neglecting after buying of which post-investment management is also very important. Investors ought to pay due attention to market conditions, fund size, and fund managers' changes so as to achieve long-term value through dynamic adjustments of portfolios after investment. The following contents discuss portfolio holding strategies from both, long-term holding and dynamic adjustment. 
For fund markets, 2020 can be called the first year of the fund in which it has created many historical highs in the fund market in China. According to the Public Fund Report 2020 data, released by the China Securities Investment Fund Industry Association on January 25, 2021, the total asset management scale of public funds in China was CNY 19.89 trillion as of the end of December 2020. It was 34.70\% higher than CNY 14.76 trillion at the end of 2019, which was a record high. However, investors who bought funds along with the flow before 2021 suffered a heavy blow because funds with a decline of more than $20 \%$ in 10 trading days were frequently seen, and the market has shifted from a bullish trend to a bearish trend, which also triggered the phenomenon of "unable to hold" where investors redeemed their assets in order to stop losses in time. In fact, funds are a form of long-term investments, so investors are supposed to broaden their investment horizons to better safeguard their long-term interests rather than blindly follow suit.

Taking Noan Growth Hybrid as an example, this paper analyzes the long-term holding return and shortterm operation return of this fund. Assuming that the calculation date of fund redemption is up to May 24, 2021, and the transaction operation is completed at 3 o'clock on the same day, the management fee at the time of fund purchase is deducted from the net value of the fund announced on each trading day. Generally, long-term holding refers to holdings in a bull and bear cycle (4 years) while short-term holding stands for holdings that are less than one year. The trend chart for the net value of historical units of Noan Growth Hybrid from January 2, 2018, to May 24, 2021, is shown in Figure 5 (the data are derived from Investing.com).

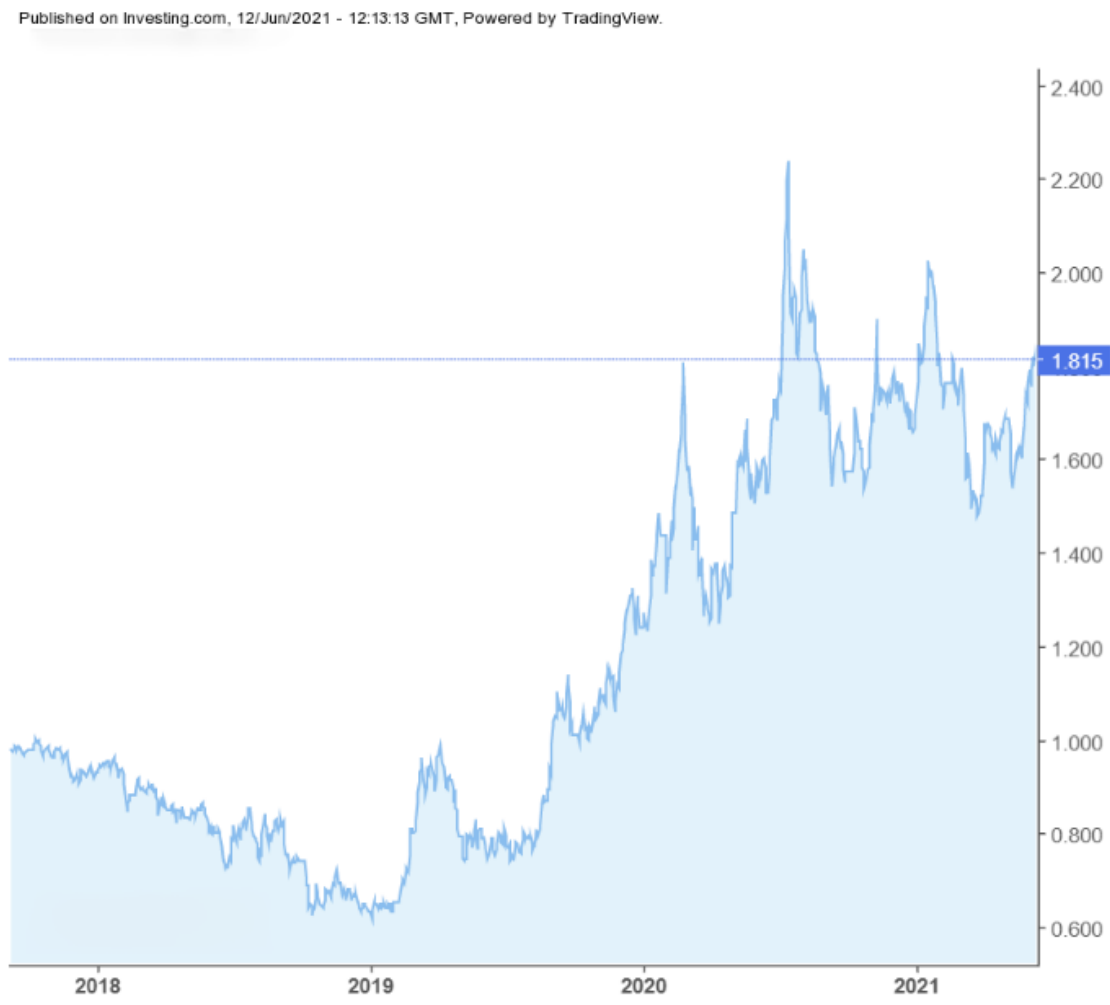

Figure 5. Trend chart for the net value of historical units

\subsection{Long-term holding}

Assuming that on January 3, 2018, investors requisitioned 10,000 yuan of Noan Growth Hybrid Fund, the net unit value on the day is 0.945 yuan, and the net unit value on the day of fund redemption is 1.625 yuan. The requisition and redemption rates are unified according to the information published by Noan Growth Hybrid Fund in Sina Finance and Economics Network. The rate standards are shown in Table 4. 
Table 4. Rate standards

\begin{tabular}{cccc}
\hline Purchase amount $(\mathrm{y})$ & Purchase rate & Ownership duration $(\mathrm{x})$ & Redemption rate \\
\hline $0 \leq \mathrm{y}<$ one million & $1.50 \%$ & $0 \leq \mathrm{x}<7$ days & $1.50 \%$ \\
One million $\leq \mathrm{y}<$ five million & $1.20 \%$ & $7 \leq \mathrm{x}<730$ days & $0.50 \%$ \\
Five million $\leq \mathrm{y}<$ ten million & $0.60 \%$ & $2 \leq \mathrm{x}<3$ years & $0.25 \%$ \\
Ten million $\leq \mathrm{y}$ & 1000 yuan & $3 \leq \mathrm{x}$ years & $0.00 \%$ \\
\hline
\end{tabular}

As shown in Table 4, the applicable requisition rate and redemption rate are $1.5 \%$ and $0.00 \%$ respectively. Since the management fee and trusteeship fee of the fund have been deducted from the net value of the fund announced on each trading day, it is not necessary to calculate the management fee during the trading process. The net income formula is Net revenue $=$ Purchase amount $\times\left\{\frac{(1-\text { Purchase rates })}{\text { Net purchase value }} \times\right.$ Net redemption value $\times(1-$ Redemption rates $)-1\}$ from which the return of the investor at redemption on May 24, 2021, is calculated as shown in Error! Reference source not found..

Table 5. Long-term holding return

\begin{tabular}{|c|c|c|c|c|c|c|}
\hline Purchase time & $\begin{array}{l}\text { Net purchase } \\
\text { value }\end{array}$ & Purchase rate & $\begin{array}{c}\text { Purchase } \\
\text { amount }\end{array}$ & Purchase share & Net revenue & Revenue rate \\
\hline January 1, 2018 & 0.945 & $1.50 \%$ & 10000 & $10,423.28$ & \multirow{3}{*}{$6,937.831$} & \multirow{3}{*}{$69.38 \%$} \\
\hline $\begin{array}{c}\text { Redemption } \\
\text { time }\end{array}$ & $\begin{array}{l}\text { Net redemption } \\
\text { value }\end{array}$ & $\begin{array}{l}\text { Redemption } \\
\text { rate }\end{array}$ & $\begin{array}{l}\text { Net redemption } \\
\text { value }\end{array}$ & $\begin{array}{l}\text { Redemption } \\
\text { share }\end{array}$ & & \\
\hline May 24, 2021 & 1.625 & $0.00 \%$ & $16,937.83$ & $10,423.28$ & & \\
\hline
\end{tabular}

\subsection{Short-term operation}

Assuming that an investor requisitioned 10,000 yuan for Noan Growth Hybrid on January 3, 2018, the net unit value on that day is 0.945 yuan, and net redemption value on September 4, 2018, is 0.839 yuan. The investor's purchase and redemption rates are collected in accordance with the information published by Noan Growth Hybrid in Sina Finance and Economics Network. The return of the investor is calculated as shown in Table 6.

Table 6. Short-term operation return

\begin{tabular}{|c|c|c|c|c|c|c|}
\hline Purchase time & $\begin{array}{l}\text { Net purchase } \\
\text { value }\end{array}$ & Purchase rate & $\begin{array}{l}\text { Purchase } \\
\text { amount }\end{array}$ & Purchase share & $\begin{array}{c}\text { Net } \\
\text { revenue }\end{array}$ & $\begin{array}{c}\text { Revenue } \\
\text { rate }\end{array}$ \\
\hline January 1, 2018 & 0.945 & 0.015 & 10000 & $10,423.28$ & \multirow{3}{*}{$-1,298.59$} & \multirow{3}{*}{$-12.99 \%$} \\
\hline Redemption time & $\begin{array}{l}\text { Net redemption } \\
\text { value }\end{array}$ & $\begin{array}{l}\text { Redemption } \\
\text { rate }\end{array}$ & $\begin{array}{l}\text { Net redemption } \\
\text { value }\end{array}$ & $\begin{array}{l}\text { Redemption } \\
\text { share }\end{array}$ & & \\
\hline September 4, 2018 & 0.839 & $0.50 \%$ & $8,701.407$ & $10,423.28$ & & \\
\hline
\end{tabular}

Judging from the two cases, the short-term operation and long-term holding, there are many reasons that can account for the situation of investors in short-term losses. From the market point of view, no one can accurately predict the trend of market price fluctuations, but frequent trading is likely to be empty, resulting in capital erosion. From the perspective of investors themselves, the ability to resist risks is weak along with no continuous and reliable source of capital. In a general way, in the process of low-level decline 
of funds, the position-holding costs can be apportioned by constantly adding positions so as to disperse the risk allocation. From the perspective of fund rate structure, the longer the fund holding period, the lower the redemption rate. Usually, no redemption fee is charged when the fund holding period exceeds 2 to 3 years. Therefore, the fund is a product that is more suitable for long-term investment.

\subsection{Dynamic adjustment strategy}

Funds indeed need to use the portfolio allocation method to disperse risk, invest, and hold for a long time. Only in this way, returns would gradually appear, which in turn reflects the value of fund investment. Importantly, investors are also supposed to emphasize on post-investment management. As the market changes, the assets in the portfolio will deviate from the allocation target. At this point, investors need to make macro decisions through dynamic adjustments and rebalancing to restore it to the proportion of longterm target allocation. The need for adjustments can be considered in the following aspects:

\subsubsection{Market changes}

When the market is bullish, it is possible to appropriately increase the allocation ratio of stock-based and hybrid funds so that portfolio investment is located at high-yield points on the efficient frontier, such as portfolios at point A and point B in Figure 4. However, at these points, they are also accompanied by high risks that investors ought to consider comprehensively according to their risk tolerance ability. When the market is bearish, investors can appropriately reduce the allocation proportion of stock funds and hybrid funds, and seek the most robust portfolio, such as portfolio C in Figure $\mathbf{4}$ or investors can also choose to gradually withdraw. That does not mean investors should reposition their portfolios every time the market changes because the fund market itself can be hard to control. Worse still, it is easy to miss steps with frequent short-term adjustments, resulting in losses. Due to the cyclical nature of macroeconomic and business operations ${ }^{[9]}$, when the net value of a fund falls, it is important to calm down and determine whether the decline is caused by the deterioration of the fundamentals of the industry and enterprises or the market sentiment. If it is caused by market sentiment, investors should be firm in their judgment and not to follow the trend.

\subsubsection{Changes in the fund}

When the fund manager changes, even in the same investment theme, the fund manager's investment personality, investment style, and investors may be different along with the fund manager's timing ability. Therefore, only by being fully aware of the investment characteristics of a fund, investors can determine whether to adjust their positions. Additionally, the current policies that are issued by the state may also affect the return of a thematic fund, so it is necessary for investors to pay attention to the announcements from fund companies, the market, and policy trends to comprehensively consider and timely adjust their investment portfolios ${ }^{[10]}$.

\section{Conclusion}

Through the theoretical guidance of the mean-variance model and capital asset pricing model, the efficient frontier of portfolio investment can be drawn to compare the returns and risks of portfolios and individual investments on the efficient frontier, which confirms the conclusion that portfolio investments can disperse risks and improve returns. At the same time, long-term holding and short-term operation of funds also have a great impact on investment returns. Long-term holding funds can help investors cope with the changing market conditions and achieve stable investment returns. Given the actual situation, the fund's investments should also be adjusted dynamically. When investing funds, residents should take into account the risks in 
the pursuit of returns, carry out portfolio investments and long-term holdings, effectively combine risk-free funds and risk funds, comprehensively analyze market conditions and fund changes, as well as timely adjust portfolio investments.

\section{Funding}

Supported by the Ministry of Education Humanities and Social Sciences Research Youth Fund Project (No. 17YJC790172) and Yunnan Province Philosophy and Social Sciences Project (No. QN2017006).

\section{Disclosure statement}

The authors declare that there is no conflict of interest.

\section{References}

[1] Markowitz HM, 1968, Portfolio Selection, Yale University Press.

[2] Sharp WA, 1963, Simplified Model for Portfolio Analysis. Management Science, 9(2): 277-93.

[3] Lintner J, 1975, The Valuation of Risk Assets and the Selection of Risky Investments in Stock Portfolios and Capital Budgets/Stochastic Optimization Models in Finance, Academic Press, 131-55.

[4] Fama EF, French KR, 2021, Multifactor Explanations of Asset Pricing Anomalies, University of Chicago Press.

[5] Li S, Xu P, 2000, Application of Markowitz Portfolio Theory Model. Economic Science, 1: 42-51.

[6] Xu Y, Li Z, 2008, Dynamic Portfolio Selection-Dynamic Mean-Variance Model Based on Income Series. System Engineering Theory and Practice, 28(8): 123-31.

[7] Sun L, 2020, Empirical Study of Markowitz Portfolio Theory Based on Python. Era Finance, 779(25): 48-9, 52.

[8] Zvi Bodi K, 2012, Investments: 9th Edition English, Machinery Industry Press.

[9] Wang Y, 2021, Fully Understand the Cyclical Characteristics of Fund Investment, Xinjiang Daily (Han), (008).

[10] Jyah Asset Management Co., Ltd., 2019, Buying Funds, to Adhere to Long-Term Holding. Modern Commercial Banks, (18): 78-9. 